\title{
Marjin Pemasaran Ternak Kerbau Ditingkat Peternak dan Pedagang Berdasarkan Harga Jual
}

\section{(Buffalo Livestock Marketing Value Margin Level and Traders Based on Price)}

\author{
S.Rusdiana dan Diana Andrianita Kusumaningrum \\ Balai Penelitian Ternak Ciawi-Bogor Po.Box. 221 Bogor \\ s.rusdiana20@gmail.com
}

\begin{abstract}
Intisari
Penelitian dilakukan di Desa Cibarani Kecamatan Cisata Kabupaten Pandeglang Propinsi Banten, tahun 2016, penelitian menggunakan metode survey lapang. Untuk mengetahui nilai dari masing masing marjin pemasaran dan nilai keuntungannya, menggunakan metoda penarikan data hasil kuisioner terhadap 10 responden peternak kerbau, 5 reponden pedagang perantara, 3 responden pedagang besar dan 2 pedagang pasar/daging dari masing-masing data dianalisis secara ekonmi. Sedangkan data primer dan data sekunder dianalisis dengan menggunakan nilai analisis marjin pemasaran. Tujuan penelitia ini adalah untuk mengetahui marjin pemasaran ternak kerbau ditingkat peternak, pedanag kecil, pedagang besar dan pedangan pasar/daging.Hasil penelitian keuntngan pada tingkat peternak marjin pemasaran I sebear Rp.575.000,- dengan share sebesar 5\%, keuntungan pada tingkat pedagang ternak marjin pemasaran II sebesar Rp.400.000,- dengan share sebesar 4,4\% dan keuntungan pada tingkat pedagang besar marjin pemasaran III sebesar Rp.403.000,- dengan share sebesar $4.5 \%$ dan keuntungan pada tingkat pedagang pasar/daging marjin pemasaran IV sebesar Rp. 305.500,- dengan share sebesar 4,3\%. Dari masing-masing marjin pemsaran dan nilai share menujukkan rasio harga ternak kerbau, yang merupakan selisih dari setiap tingkat pedagang ternak.
\end{abstract}

Kata kunci: marjin pemasaran, kerbau ditingkat, harga jual

\begin{abstract}
The research was conducted in Cibarani Village, Cisata Subdistrict, Paneglang Regency, Banten Province, in 2016. The research used field survey method. To know the value of each marketing margin and its profit value, using questionnaire method of questionnaire data to 10 respondents of buffalo breeders, 5 intermediary traders, 3 large traders and 2 market/meat traders from each data were analyzed economically. The while primary data and secondary data are analyzed by using value of marketing margin analysis. The purpose of this research is to know the marketing margin of buffalo cattle at the level of farmers, small pedanag, traders and market/meat pedangan.Hasil research results at the level of breeders marketing margin I sebear Rp.575.000,- with a share of 5\%, profit on the level of cattle traders marketing margin II amounting to Rp.400.000,- with a share of $4.4 \%$ and profit at the level of trader III marketing margin of Rp.403.000,- with a share of $4.5 \%$ and profit at market/meat market margin level of marketing IV of Rp.305,500,- with a share of $4.3 \%$. From each of the interest margin and the share value shows the buffalo price ratio, which is the difference of each level of livestock traders.
\end{abstract}

Keywords: marketing margin, buffalo level, selling price

\section{Pendahuluan}

Tingkat kebutuhan konsumsi daging kerbau di Provinsi Banten terus meningkat, sesuai dengan jumlah penduduk propinsi Banten. Ironisnya, peningkatan kebutuhan akan daging kerbau bagi masyarakat Banten tidak 
diimbangi dengan jumlah populasi kerbau yang ada pada saat ini. Marjin pemasaran sebagai penanganan keluar masuk ternak kerbau di pasar ternak, bak untuk ternak potong maupun ternak bibit, sehingga tercatat. Pada umumnya selalu melibatkan berbagai kelompok pedagang seperti pedagang desa, pedagang kecamatan, pedagang Kabupaten, pedagang antar Provinsi dan pedagang pengecer. Semakin besar biaya pemasaran, akan semakin besar pula jaringan informasi, sehingga keuntungan yang akan diperoleh juga akan semakin besar. Menurut Rusdiana dan Praharani (2015) bahwa, resiko biaya yang dikeluarkan oleh setiap marjin pemasran akan semakin besar pengaruhnya terhadap penge-luaran usaha. Pasar ternak dapat terjadi akibat kurangnya kompetisi di antara pedagang desa akibat jumlah pedagang ternak yang terbatas.

Pentingnya marjin pemasaran ternak, di Kabupaten Panegleng, terhadap para pelaku usaha, baik sebagai pedagang kecil, sedang dan besar, Abubakar (2002), menyatakan bahwa marjin pemasaran, untuk memudahkan cara penjualan suatu barang yang telah dihasilkan oleh produsen, sehingga barang dapat terjual dengan cepat. Pedagang desa masih dirasakan sangat membantu peternak, sehingga pedagang desa tidak mungkin dihilangkan dari marjin pemasaran (Rusdiana dan Adawiyah 2013). Namun peternak dihadapkan pada posisi tawar yang lemah, mereka buta informasi, tidak mengetahui informasi harga ternak, terlebih lagi pada saat peternak memerlukan uang, sehingga ternak terjual harganya menjadi tidak wajar (Sumitra et al., 2013). Emhar et al. (2014), menjelaskan bahwa margin pemasaran merupakan bagian biaya yang dibayarkan dan pendapatan yang diterima oleh setiap mata rantai yang terlibat dalam proses pemasaran. Marjin pemasaran ternak merupakan aspek yang terpenting di dalam usaha ternak kerbau.

Produksi yang dihasilkan harus berkuantitas dan kualitas baik, tergantung kondisi pasar yang tidak mengarah pada persaingan sempurna (non-perfect competition market). Jumlah pedagang ternak yang terlibat cukup banyak tetapi dalam kegiatannya para pedagang ternak kerbau seringkali dikendalikan oleh satu atau beberapa pedagang lain yang bersipat monopolis. Margin merupakan rantai pemasaran yang dapat didefinisikan menjadi dua bagian yaitu, margin pemasaran yang merupakan perbedaan antara harga yang dibayarkan oleh konsumen dengan harga yang diterima oleh produsen ternak. Hal ini menyebabkan terbentuknya sistem pasar monopsoni/oligopsoni yang terselubung. Walaupun keadaan pasar tampaknya bersaing sempurna karena jumlah pedagang yang banyak tetapi sebenarnya dikuasai oleh pedagang besar. Masing masing jalur pemasaran mempunyai peran dan fungsi tersendiri dalam proses untuk mendapatkan keuntungan. Tujuan tulisan ini adalah untuk mengetahui nilai marjin pemasaran ternak kerbau ditingkat 
peternak dan pedagang, berdasarkan harga jual ternak kerbau.

\section{Materi dan Metoda}

\section{Lokasi dan waktu penelitian}

Lokasi penelitian di Desa Cibarani Kecamatan Cisata Kabupaten Paneglang Propinsi Banten, pada tahun 2016, penelitian menggunakan metode survey lapang, penelitian ini menggunakan metoda deskriptif, kuantitatif dan analisis ekonomi pendapatan, pengambilan data ini digunakan sebagai gambaran umum untuk mengetahui nilai keuntungan dari masing-masing marjin pemasaran ternak kerrbau, secara sistematis faktual, yang dihasilkan melalui informasi tertulis dari peternak dan pedagang ternak kerbau. Marjin pemasaran ternak kerbau, sebagai data yang diperoleh hasil penelitian, sehingga dapat diungkapkan kebenaran dari hasil survey lapang. Diperoleh suatu makna dan implikasi dari masalahnya, masalah tersebut dapat dipecahkan melalui analisis nilai marjin pemasaran ternak kerbau pada peternak dan pedagang ternak.

Marjin pemasaran merupakan badan atau lembaga yang menyelenggarakan kegiatan atau fungsi pemasaran dengan menggerakkan aliran barang dan sebagai agen dari pemilik barang. Untuk mengetahui nilai jual dari masing masing marjin pemasaran dan nilai keuntungannya, diperlukan metoda penarikan sampel hasil kuisioner dan wawancara dari 10 responden peternak kerbau, 5 reponden pedagang perantara, 3 (tiga) responden pedagang besar dan 2 (dua) responenden pedagang pasar, dari masing-masing data dianalisis secara ekonomi pendapatan.

\section{Metoda Penelitian.}

Data primer yang dikumpulkan dari responden peternak, dan pedagang ternak yang meliputi identitas peternak, sistem pemasaran ternak kerbau dan harga jual ternak kerbau, data skunder diperoleh dari Dinas Pertanian dan Peternakan setempat, kemudian data primer dan data skunder ditabulasi dan dianalisis dengan menggunakan analisis nilai marjin pemasaran, jumlah keuntungan yang diperoleh dari masing-masing jalur pemasaran, digunakan dengan rumus:

$\mathrm{Y}=\mathrm{y} 1+\mathrm{y} 2+\mathrm{y} 3+\mathrm{y} 4+\mathrm{x}=$ (peternak + blantik/ kecil + pedagang besar + pasar + keuntungan)

Dimana:

$$
\mathrm{y}=\text { peternak }
$$

$\mathrm{y} 1=$ pedagang (perantara/

blantik desa)

$\mathrm{y} 2=$ pedagang besar

$\mathrm{y} 3=$ pedagang pasar/daging

$x=$ share keuntungan dari

masing-masing marjin $(\mathrm{Rp} / \%)$

Menurut Ramadhan (2009) dan Rosganda et al., (2013) mendefinisikan bahwa dari margin pemasaran sebagai perbedaan harga yang dibayar oleh konsumen. Marjin pemasaran adalah selisih antara harga jual pada tingkat pengecer dengan harga jual pada tingkat produsen, selisih harga dihitung melalui persentase. Harga yang diterima oleh peternak, 
merupakan selisih antara harga di tingkat konsumen ( $\mathrm{Hk})$, dengan harga di tingkat peternak produsen ( $\mathrm{Hp})$, dengan rumus : Mrp $=\mathrm{Hp} 1-\mathrm{Hp} 2$. (Hk+Hp).

Dimana:

$$
\begin{aligned}
& \text { Mrp : Margin pemasaran, } \\
& \text { Hp1 : Harga pemasaran, } \\
& \text { Hp2 : Harga pedagang }
\end{aligned}
$$

Majin pemasaran terdiri dari biaya pemasaran dan keuntungan. Semakin besar biaya pemasaran, akan semakin besar keuntungan yang diperoleh di setiap marjin. Margin pemasaran hanya menunjukkan selsisih harga tanpa .memperhatikan jumlah yang diperdagangkan oleh produsen (peternak). Nilai dari margin pemasaran adalah selisih harga jual dengan jumlah transaksi. Menurut Ramadhan (2009), bahwa, margin pemasaran dapat diformulasikan sebagai berikut: $\mathrm{MP}=\mathrm{BP}+\mathrm{KP}$, dimana, BP: Biaya Pemasaran, KP:, Kentungan peternak dan pedagang ternak. Marjin pemasaran adalah atau jalur yang digunakan untuk memasrkan produk yang dihasilkan baik secara langsung maupun tidak langsung. Untuk memudahkan konsumen dalam pemilihan suatu produk yang dijual (bergerak maupun tidakbergerak) dari produsen sampai berada di tangan konsumen.

\section{Hasil dan Pembahasan}

\section{Perkembangan ternak kerbau di peternak}

Peternak kerbau di Desa Cibarani Kecamatan Cisata Kabupaten Pandeglang tercatat sebagai anggota kelompok peternak terbanyak sebanyak 35 peternak. Hampir semua peternak kerbau cara pengelolaan usahanya terlihat masih semi intensif. Ternak kerbau yang dipelihara oleh kelompok peternak, sudah lama dan secara turun temurun dalam usaha ternaknya. Pemasarann ternak kerbau masih secara tradisional, banyak dilakukan dengan cara penjualan ditempat atau di kandang peternak, dengan pedagang/balntik desa. Kebutuhan akan konsumsi daging kerbau setiap tahunnya selalu meningkat, peternak cara penjualannya tergantung pada kondisi kebutuhan ekonomi peternak dan lingkungan peterna. Hal yang sama dikemukakan Kusnadi (2007) dan Prawirodigdo dan Utomo (2011) bahwa, pada prinsipnya usaha ternak kerbau layak secara ekonomi, peternak mendapat keuntungan yang optumal sesuai dengan keinginannya.

Layak tidaknya pengembangan usaha ternak kerbau tergantung pada tiga faktor yaitu ketersediaan pakan (feedstock availability) yang longgar, kesesuaian ekologi lingkungan dan penerimaan masyarakat (public acceptance) dan eksitensi ternak kerbau. Secara sosial, teknis dan ekonomi sangat diterima oleh etani peternak dan masyarakat sekitar. Ternak kerbau dapat terus dikembangkan oleh masyarakat atau peternak di Kabupaten Paneglang Banten disamping sebagai proses juga sangat mendukung perputaran perekonomian peternak.

\section{Fluktuasi harga ternak kerbau}


Kepercayaan peternak kerbau di Kabupaten Paneglang Banten terhadap pedagang pelantara/blantik desa sangat tinggi. Peternak melakukan aktivitas penjualannya lebih banyak di kuasai oleh pedagang perantara. Keberadaan pedagang pelantara, dianggap oleh peternak sangat membantu sekali dalam kelancaran jual beli ternak kerbau. Pedagang pelantara memegang teguh kepercayaan peternak, pedagang perantara, membantu peternak dari segi penyediaan dana untuk usaha ternak kerbau. Namun pedagang perantara tidak merugikan peternak, sehingga peternak sangat percaya penuh. Nilai beli pedagang pelantara lebih rendah dibandingkan dengan harga pasar, walaupun demikian peternak tetap merasa senang dan tidak merasa dirugikan oleh pedagang pelantara. Pedagang pelantara memperhitungkan ongkos dan tanaga kerja, nilai harga jual ternak kerbau dapat berubah sewaktuwaktu. Dimana saat menjeang hari Raya Idul Adha dan tahun baru, nilai jual ternak kerbau melambung tinggi, kemudian setelah hari raya berlalu, harga nilai jual ternak kerbau kembali ke harga semula (Rusdiana dan Herawti 2008).

\section{Marjin pemasaran ternak kerbau}

Peternak kerbau di Pandeglang usahanya dapat dipokuskan kedalam kelompok usaha ternak, dengan membentuk koperasi atau usaha bersama. Masing-masing kelompok dapat memelihara ternak kerbau dengan cara pembesaran dan bibit, agar peternak terlindungi dengan harag pasar. Dukung kelembagaan pasar sangat dibutuhkan oleh setiap peterak, agar informasi yang diperoleh cukup akurat dan benar. Disamping itu perlu dengan adanya kelompok peternak secara teknis dapat melancarkan pemasaran ternak. Sesuai dengan pendapat Zivenge dan Karavina (2012), bahwa peternak dapat didorong untuk bergabung dalam kelompok atau koperasi agar dapat meningkatkan kesempatan peternak dalam mengakses input produksi dan nilai keuntungan yang optimal. Menurut Girei et al., (2013), Hangara et al., (2012) dan Koesmara et al., (2013) bahwa, dengan adanya lembaga pasar ternak, maka peternak akan terjamin dalam transaksi jual beli ternak. Dengan adanya lembaga pemasaran sangat membantu para peternak, pedagang kecil, dan pedagnag besar.

Disamping itu pula pasar ternak di Kabupaten Paneglang Banten sangat berperan sekali dalam menentukan harga ternak. Pasar ternak pada dasarnya adalah untuk memenuhi kebutuhan konsumen ternak, dengan demikian akan memberikan dampak positif. Lemabaga pasar dapat mengkoordinir pedagang ternak, sehingga harga jual ternak di setiap pedagang tidak berfluktuatip, peternak merasa terlindungi dengan tidak kerahasiahan harga ternak (Dinas Peternakan Kabupaten Pandeglang Propinsi Banten. 2017). Harga ternak kerbau di pasar ternak akan terlindungi, dan apabila lembaga pemasaran dapat mengontrol harga. Kondisi peternak sampai saat ini tidak merasa tertekan dengan harga pedagang/blanti Desa, karena peter- 
nak sudah percaya (Rusdiana dan Soeharsono 2017). Alur marjin pemasaran ternak kerbau di Kabupaten
Paandeglang Banten terlihat pada Gambar 1.

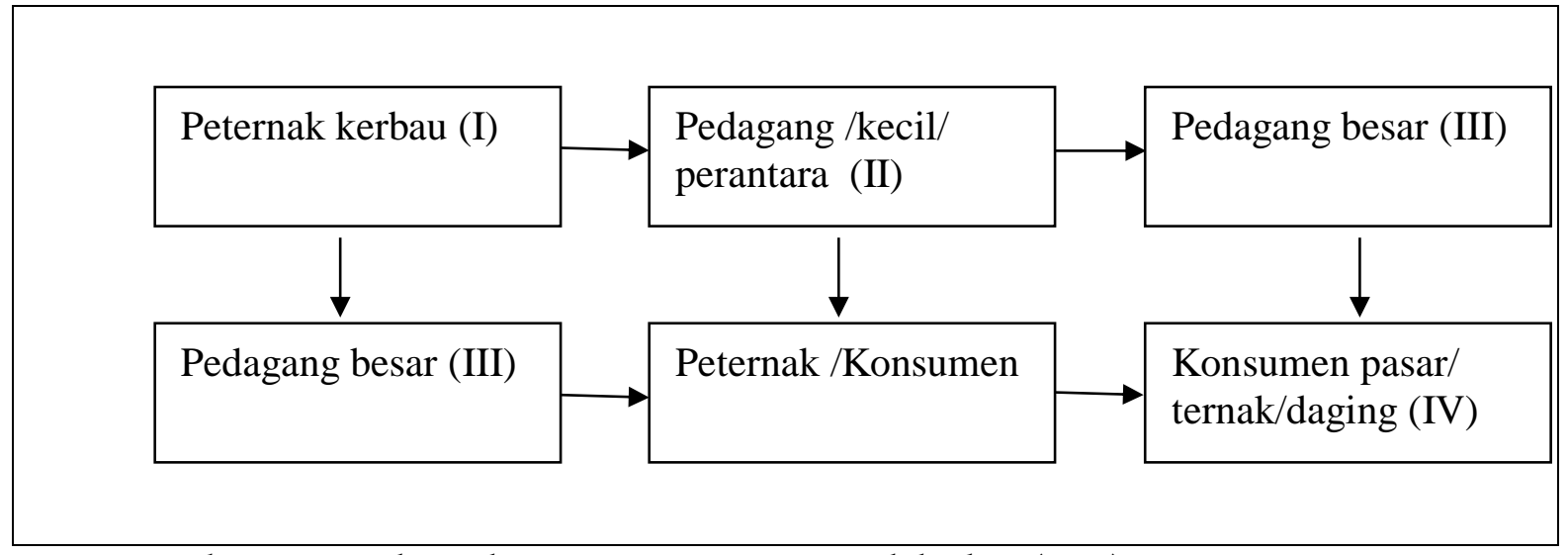

Keterangan : ilustrasi rangkaian kegiatan pemasaran ternak kerbau (2016)

Gambar 1. Marjin Pemasaran Ternak Kerbau di Peternak

Berdasarkan ilustrasi rangkaian Gambar.1, bahwa, marjin pemasaran ternak ketbau sebagai rantai yang dapat memperlacar arus ekonomi peternak, baik di pedesaan maupun diperkotaan. Peternak dapat menjual ke pedagang pengmpul, pedagang besar, pedagang pasar/daging dan konsumen akhir. Pedagang pengum-pul dapat melakukan penjualnya melalui pedagang besar, pedagang pasar/daging, konsumen akhir. Marjin pemasaran dapat dikatakan sebagai rantai-rantai pemasaran atau tataniaga yang utuh dan tidak berbelitbelit.Marjin pemasaran dapat menentukan nilai harga jual ternak kerbau pada posisi tawar harga ternak di masing-masing marjin. Pedagang pengumpul sangat aktif melakukan usahanya, mengingat peternak dalam penjualan ternak selalu melalui ke pedagang pengumpul/ blantik Desa.
Peterrnak yang telah di koordinir diharapkan dapat menghasilkan produk yang baik dan pada akhirnya dapat meningkatkan pendapatan peternak.

\section{Analisis marjin pemasaran ternak kerbau}

Marjin pemasaran mempunyai tahapan dan fungsi yang sangat strategik, sebagai perantara. Untuk memudahkan pemindahan hasil produk peternakan dari produsen ke konsumen. Penjualann ternak kerbau melalui marjin pemasaran I sebagai peternak, sebagai pedagang/ tengkulak marjin pemsaran II, sebagai pedagang besar marjin pemasaran III dan pedagang pasar/daging marjin pemasaran IV. Kemudian akan diperoleh nilai share dari masingmasing marjin pemasaran, sehingga keuntungan dan share akan berbeda. Perbedaan keuntungan dan share pada 
tingkat peternak, pedagang perantara/ blantik desa, pedagang besar maupun pedagang pasar/daging (Suarda 2009),

Pada nilai marjin pemasaran I ditingkat peternak, pembelian ternak kerbau jantan dengan nilai harga beli awal, perkiraan umur ternak kerbau sekitar 2,1 tahun, asumsi atau diperkirakan bobot badan hidup sebanyak $225 \mathrm{~kg} /$ ekor, dengan nilai jual jual, harga daging sebesar Rp.40.000,/ kg atau sebesar Rp.9.000.000,-/ekor. Nilai jual ternak kerbau dengan perkiraan umur akhir sekitar 3,5 tahun dan bobot badan hidup sekitar $325 \mathrm{~kg}$. Perkiraan nilai jual harga daging sebesar Rp.41.000,-/ $\mathrm{kg}$ atau harga sebesar Rp.13.325.000,-/ekor. Biaya pemeliharaan selama 1,6 tahun, diperkirakan untuk baya tenaga kerja keluarga peternak sebesar Rp.10.000,/hari/tahun atau sebesar Rp.3.600.000,/tahun dan perkiraan biaya perbaikan kandang sebesar Rp.150.000,-/tahun. Jumah biaya produksi dan pembelian ternak kerbau sebesar Rp.12.750.000,/tahun atau share 5\%, keuntungan yang diperoleh marjin pemasarn I sebesar Rp.575.000,-/tahun/peternak

Nilai marjin pemasaran II ditingkat pedagang tengkulak/blantik desa, nilai jual daging sebesar Rp.43.000,-/ kg atau sebesar Rp.13.997.000,-/ekor keuntungan kotor sebesar Rp.650.250,- atau share 6\%. Selama penampungan 1-3 hari sebelum hari pasar ternak untuk dijual ke pedagang besar atau ke pasar ternak, maka ada penambahan biaya pakan dapat diasumsikan ke dalam biaya tenaga kerja sebesar Rp.150.000,- dan biaya transportasi diasumsikan sebesar Rp.100.000,-. Biaya yang dikeluarkan oleh marjin pemasaran II sebesar Rp.350.000,-/periode, kkeuntungan marjin pemasaran II sebesar Rp.400.000,-/pedaagang perantara. Nilai marjin pemasaran III ditingkat pedagang besar, nilai harga jual daging sebesar Rp.45.000,-/kg atau sebesar Rp.14.625.000,-/ekor, keuntungan kotor sebesar Rp.628.000,- atau share $4,5 \%$. Biaya pemeliharaan ternak kerbau sebelum terjual atau dipotong sebesar Rp.200.000,- dan biaya lainnya, diasumsikan sebesar Rp.25.000,-.

Jumah biaya yang dikeluarkan oleh marjin pemasaran III sebesar Rp.225.000,-, nilai keuntungan marjin pemasaran III sebesar Rp.403.000,/ pedagang besar. Marjin pemasaran IV ditingkat pedagang pasar/daging dengan nilai harga jual daging sebesar Rp.47.000,-/ kg atau sebesar Rp.15.275.000,-/ekor, keuntungan kotor sebesar Rp.650.000,- atau share $4,5 \%$. Biaya pemeliharaan untuk tenaga kerja penjualan daging dan pembayaran kontribusi sebesar Rp.235.000,-/hari, pembayaran paket karcis dari lembaga pasar ternak sebesar Rp.10.000,-/hari dan resiko daging tidak habis sebesar Rp.100.000,Biaya yang dikeluarkan oleh marjin pemasaran IV sebesar Rp.345.000,/pedagang pasar, keuntungan nilai marjin pemasaran IV sekitar Rp.305.500,-/pedang pasar/daging. Coetzee et al., (2005), menyatakan bahwa, pemasaran ternak sangat berperan penting pada proses transformasi skala usaha rakyat, 
menuju usaha yang bersifat komersial. Untuk melihat analisis dari masingmasing marjin pemasran dan share terlihat pada Tabel 1.

Tabel 1 menujukkan bahwa nilai share tertinggi pada posisi marjin pemasran I sebagai peternak dengan share $5 \%$. Kemudian marjin pemasaran III dengan share $4,5 \%$, sedangkan marjin pemasaran II dan IV dengan share masing-masing $4,4 \%$ dan $4,3 \%$. Masing-masing nilai

Tabel 1. Analisis marjin pemasaran ternak kerbau di peternak (Rp.000/share \%)

\begin{tabular}{lllll}
\hline Uraian Peternak dan pedagang & Nilai jual & $\begin{array}{l}\text { Resiko } \\
\text { biaya }\end{array}$ & Keuntungan & $\begin{array}{l}\text { Share } \\
\%\end{array}$ \\
\hline Marjin I, Peternak n-10 & 13,32 & 12,75 & 0,575 & 5 \\
$\begin{array}{l}\text { Marjin II Pedagang perantara n-5 } \\
\text { Marjin III Pedagang besar n-3 }\end{array}$ & 13,99 & 0,350 & 0,400 & 4,4 \\
$\begin{array}{l}\text { Marjin Pedagang } \\
\text { pasar/daging n-2 }\end{array}$ & 14,94 & 0,225 & 0,403 & 4,5 \\
\hline
\end{tabular}

Sumber data di olah (2016)

marjin pemasaran memperoleh keuntungan hampir sama. Baik pada peternak, pedagang perantara, kecil/ blantik desa, pedagang besar, dan pedagang pasar/daging. Masingmasing marjin pemasaran mengimbangi nilai jual ternak kerbau, marjin pemasran I atau dari harga sebelumnya.

\section{Marjin Pemasaran Ternak Kerbau}

Marjin pemasaran I peternak mempunyai margin yang lebih besar dibanding dengan margin pemasaran II, III dan IV. Marjin pemasaran III dan IV dapat dilakukan lebih panjang, dikarenakan posisi marjin pemasran II dapat melangkah ke posisi marjin pemasran IV atau ke konsumen langsung. Untuk marjin pemasaran I sebagai peternak, bisa melangkah dalam pemasarannya ke posisi marjin IV konsumen akhir. Namun jarang dilakukan oleh setiap kelompok peternak di Kabupaten Paneglang.
Nilai share yang tertinggi pada marjin pemasaran I dan III, nilai share lebih tinggi sebesar $5 \%$ dan 4,5\%. Sedangkan untuk marjin pemasaran II dan IV posisi share lebih rendah sebesar 4,4 dan 4,3\%. Hal tersebut disebabkan marjin pemasaran II dan IV terjadi, ketika kondisi ternak kerbau belum terjual, sebagai penampungan pertama. Untuk sementara menunggu sebagaian ternak kerbau berikutnya yang akan dijual oleh marjin pemasaran I sebagai peternak. Penambahan biaya untuk pakan, tenaga kerja dan transportasi dihitung berdasarkan waktu kerja usaha menunggu hari pasar ternak.

Marjin pemasran II dan IV, bertambahnya biaya pengeluaran yang cukup tinggi. Posisi tawar ternak kerbau masih dapat dilakukan disetiap marjin, karena harga masih dipegaruh oleh harga awal. Setiap marjin memperoleh hak untuk menawarkan ternak kerbau lebih tinggi dari pada 
harga sebelumnya. Harga dapat terjadi apabila konsumen merasa cocok dengan harga yang ditawarkan oleh pedagang. Setiap marjin akan berbeda nilai jualnya, karena ternak kerbau dari posisi yang berbeda. Pengeluaran biaya dari setiap marjin akan berbeda, tergantung pada kondisi lingkungan. Keuntungan yang diterima oleh setiap marjin pemasaran II, III dan IV hampir sama. Marjin pemasaran II, III dan IV sebagai pedagang ternak kerbau menanggung resiko lebih besar dan membutuhkan waktu yang lebih lama. Setiap marjin pemasaran tidak saling mempengaruhi harga dengan marjin pemasaran lainnya, masing-masing marjin mempunayi posisi tawar tersendiri. Pedagang bebas untuk menjual hasil produksinya secara langusng ke konsumen maupun melalui pedagang lainnya (Kotler et al., 2005).

\section{Kesimpulan}

Marjin pemasaran ternak kerbau di Kabupaten Paneglang Banten, mempunyai keuntungan yang berbeda. Keuntungan pada tingkat peternak marjin pemasran I sebear Rp.575.000,dengan share sebesar 5\%. Keuntungan pada tingkat pedagang ternak marjin pemasaran II sebesar Rp.400.000,dengan share sebesar $4,4 \%$. Keuntungan pada tingkat pedagang besar marjin pemasaran III sebesar Rp.403.000,- dengan share sebesar 4.5\%. Keuntungan pada tingkat pedagang pasar/daging marjin pemasaran IV sebesar Rp. 305.500,- dengan share sebesar $4,3 \%$.
Masing-masing marjin dan nilai share menujukkan rasio harga yag berbeda, merupakan selisih dari setiap marjin. Setiap marjin pemasaran tidak saling mempengaruhi nilai jual baik ditingkat peternak, pedagang besar maupun pedagang daging/pasar. Kebutuhan konsumen daging dan ternak di Kabupaten Paneglang dapat dipengaruhi oleh lingkungan sosial ekonomi dan budaya masyarakat setempat.

\section{Daftar Pustaka}

Abubakar R., 2002. Ekonomi Pemasaran, Proyek dan Pengadaan Buku Sekolah Ekonomi. Diterbitkan oleh PT Sumber Bahagia Offset Jakarta Ediso ke 2, hal.1-254

Coetzee, L., B. D. Montshwe and A. Jooste. 2005. The marketing of livestock on communal lands in the Eastern Cope Province: constraints, challenges and implications for the extension services S. Afr. Agric. Ext. 34: 81103.

Dinas Peternakan Kabupaten Pandeglang Propinsi Banten. 2017. Populasi ternak kerbau di Banten, Laporan Tahun 2017, Desember hal. 152.

Emhar. A., J. M. M. Aji, dan T. Agustina. 2014. Analisis rantai pasokan (supply chain) daging di Kabupaten Jember. Jurnal 
Berkala Ilmiah Pertanian Vol. 2 2014. hal,. 1: 53.

Gittinger. 1986. Analisis Ekonomi ProyekProyek Pertanian. Edisi Kedua. Universitas Indonesia, Jakarta.

Girei, A. A., B. Dire and B. H. Bello. 2013. Assesment of cost and returns of cattle marketing in central zone of Adamawa State, Nigeria. British J. Marketing Studies 1: 1-10.

Hangara. G. N., M.Y. Teweldemedhin and I.B. Groenewold. 2012. Assessment of the constraints of cattle supply chain management in Namibia: case study of Omahele Communal Farmers. African J. Agric. Research 7: 4876-4884.

Koesmara, Sudi Nurtini, dan I Gede Suparta Budisatria. 2015. Faktorfaktor yang mempengaruhi margin pemasaran sapi potong dan daging sapi di kabupaten aceh besar Buletin Peternakan Vol. 39 (1): 57-63,

Kusnadi.U. 2007. Kelayakan usaha kerbau untuk penghasil bibit dan daging dibeberapa agroekosistem, Prosiding Seminar Nasional Teknologi Peternakan dan Veteriner. Puslitbang Peternakan Bogor, 13-14 Agustus 2008, hal, 186-192.
Kotler, P., S. H. Ang, S. M. Leong, dan C. T. Tan. 2005. Manajemen Pemasaran: Sudut Pandang Asia Edisi Ketiga. PT Indeks, Jakarta.

Prawirodigdo S., dan B. Utomo. 2011. Peluang pengembangan ternak kerbau rawaa di kantong bibit sapi potong lokal, grobogan ditinjau dari aspek ketersediaan pakan. Prosiding Seminar Nasional, Puslitbangnak bekerjsama dengan Dinas Peternakan Nasional Lebak, Lebak Direktorat Perbibitan, Direktorat Jenderal Peternakan, Lebak-Banten 2-4 Nopember 2010, hal, 174-181.

Rusdiana, S dan Tati Herawati. 2008. Pemeliharaan ternak kerbau dalam sistem usahatni terhadap pendapatan keluarga di Kecamatan Cieumas kabupaten Sukabumi. Prosiding Seminar dan Lokakarya Nasional Kerbau Puslitbangnnak bekerjasama dengan Dinas Peternakan Propinsi Sulawesi Selatan, Dinas Pertanian dan pangan Kabu paten Tana Toraja, Tim: A, Bamualim, Chalid Talib dan Tati Herawati, Tana Toraja 24-26 Oktober 2008. hal. 91-96

Ramadhan.W. 2009. Analisis marjin pemasaran sapi potong di Kecamatan Singosari Kabupaten Malang Propinsi Jawa Timur/ Wahyu-gayo.blogspot.com/analisismargin-pemasaran-sapi-potong.ht. berupa bulletin. Mahasiswa 
Sekolah Tinggi Penyuluhan

Pertanian Malang, di akses 15 Juli 2013

Rusdiana.S. dan A, M. Bamualim. 2010. Efisiensi pengembangan model usaha pemeliharaan kerbau di tingkat peternak di Kabupaten Bogor. Prosiding Seminar dan Lokakarya Puslitangnak Nasional, dengan Dinas Peternakan Propinsi Jawa Tengah, Pemerintah Daerah Kabupaten Brebes dan Direktorat Berbibitan, Direktorat Jeneral Peternakan, Brebes 11-13 Nopemebr 2009, hal. 66-71.

Rusdiana.S., dan Adawiyah, C.R. 2013. Analisis ekonomi dan prospek usaha tanaman dan ternak dilahan perkebunan kelapa. Sepa. Jurnal Ssial Ekonomi Pertanian dan Agribisnis Vol. 10 No.1 September 2013. 118-131.

Rosganda, E., Rusdiana, S., dan E, Romjali. 2013. Marjin pemasaran ternak kambing dalam pemenuhan kebutuhan konsumen: Analisis ekonomi. Prosiding Seminar Nasional, Program Studi Agribisnis Fakultas Pertanian, UNS Surakarta Mei 2013, hal..331-345

Rusdiana.S., IGM. Budiarsana dan Sumanto. 2014. Analisis pendapatan usaha pertanian dan peternakan kerbau di kabupaten Lombok Barat Propinsi Nusa Tenggara Barat (NTB). JAREE-IPB. Jurnal Ekonomi Pertanian, Sumber daya dan Lingkungan. Vol. 1 No.2. Oktober 2014. hal. 56-67.

Rusdiana, S., dan L. Praharani. 2015. Estimated value of live buffalo frice in the economic analysis of the income $o$ farmers in the village. Proseeding International seminar on anilam indutry, Faculty of Animal Science Bogor Agricultura University IPB, September 17-18-2018, hal.388293.

Rusdiana, S. and Soeharsono. 2017. Farmer group performance bali cattle in luwu district east: the economic analysis. The International Joural Of Trovical Veterinery and Biomedical Research, The Faculty of Veterinery Medicine Syiah Kuala University, May 2017, Vol. 2(1):18-29

Suarda, A. 2009. Saluran pemasaran ternak sapi potong di Sulawesi Selatan. Jurnal Sains dan Teknologi Peternakan Juni 2009, Vol 9 (2): 113-118.

Sumitra, J., T. A. Kusumastuti, dan R. Widiati. 2013. Pemasaran sapi potong di Kabupaten Ogan Komiring Ilir Propinsi Sumatera Selatan. IGM, Oktober 2017, 
Buletin Peternakan Vol.37(1): 4958.

Syafaat.N.A. Agustin, T.Pradji, Mariani, M. Setiadji dan Wirwan. 1995. Studi Kajian SDM dalam Menunjang Pembangunan Pertanian Rakyat Terpadu di KTI. Puslit Sosial Ekonomi Pertanian Bogor, Proseding Sosial Ekonomi September 2009, hal.495-406.

Zivenge, E. and C. Karavina. 2012. Analysis of factors influencing market channel access by communal horticulture farmers in chinamora District, Zimbabwe. J. Dev. Agric. Econ. 4: 147-150. 